\title{
How effective is kaolin clay for the creation of a perfect hydraulic interface contact between materials?
}

\author{
Evy Vereecken ${ }^{1, *}$, Petra Schůtová ${ }^{2}$, and Staf Roels ${ }^{1}$ \\ ${ }^{1}$ KU Leuven, Department of Civil Engineering, Building Physics Section, Kasteelpark Arenberg 40, 3001 Leuven, Belgium \\ ${ }^{2}$ UCEEB, CVUT in Prague, Třinecká 1024, 27343 Buštěhrad, Czech Republic
}

\begin{abstract}
Due to interface phenomena such as compaction pores, a mismatch of the pore structure, etc., moisture transfer in multi-layered building elements can deviate from the moisture transfer observed for the combination of the separate materials. Several studies on interface phenomena make use of kaolin clay to provide - as a reference - a perfect hydraulic contact between materials. This paper investigates, based on a series of imbibition experiments, whether kaolin clay truly creates this perfect contact, and thus, whether the hydraulic interface resistance between materials can be nullified by use of kaolin clay. For a low absorptive material or a large distance between the contact interface and the water surface, composite samples put together with kaolin clay show an identical water uptake curve as observed for homogeneous samples. For a material with a high absorptivity and a contact interface closer to the water plain, however, even with kaolin clay a hydraulic interface resistance is observed and estimated to be in the order of $6000 \mathrm{~m} / \mathrm{s}$ till $12000 \mathrm{~m} / \mathrm{s}$. If present, such an interface resistance is furthermore shown to have no impact on the water uptake curve for samples composed of low absorptive bricks or with a contact interface further away from the water plain.
\end{abstract}

\section{Introduction}

A good understanding of the moisture transfer in building systems is of main importance in many risk assessments. In this respect, the deviation between the moisture transfer in multi-layered building materials, such as brick-mortar composites, and the moisture transfer observed for the combination of the separate materials is put forward as an important issue by several researchers, a.o. [1-5]. After all, a poor estimate of this deviation might result in unreliable risk assessments. For instance, when dealing with masonry exposed to winddriven rain or rising damp, an overestimation of the inor upward moisture flow corresponds to an underestimation of the moisture in the outer or lower bricks and mortar layers. Hence, frost and other damage patterns might be overlooked.

In the literature, several reasons are specified explaining the delay of the moisture transport across material interfaces; a.o. the presence of compaction pores [1-3], a mismatch between the pore structure of both materials [1, 6, 7], mortar particles transported into the pores of the second material, an interface zone with modified (mortar) properties [1, 3 ] and micro-cracks [3]. In numerical simulations, all of these phenomena together can be taken into account by use of a hydraulic interface resistance or permeability $[1,3,5]$. The presence and order of magnitude of this interface resistance is often investigated by comparing the moisture transport in a multi-layered sample with a real material interface to the moisture transport in the same material combination but with a perfect hydraulic interface contact in between [3, 8, 9]. To achieve the latter, typically kaolin clay is applied $[3,6,8,9,10,11]$. The question arises, however, if kaolin clay absolutely nullifies the hydraulic interface resistance between materials.

This paper investigates, for a series of imbibition experiments, to what extent kaolin clay is effective in the creation of a perfect hydraulic interface. This way, the paper gives a first view on the extent to which and the boundaries for which kaolin clay can be applied to provide a perfect hydraulic contact in experimental test setups or test samples. In order to analyse the effectiveness of kaolin clay, experimentally measured water uptake curves are analysed. Additionally, the measured data are compared with numerically simulated water uptake curves and the need and impact of the implementation of a hydraulic interface resistance in these simulations is studied. The paper is organised as follows. Section 2 first describes the dimensions and the preparation of the different test samples, the hygric properties and the boundary conditions of the imbibition experiment. Additionally, the numerical methodology applied to estimate the hydraulic interface resistance is explained. Both materials with a low as well as a high absorptivity are analysed in the study. Furthermore, the impact of the distance from the contact interface to the

\footnotetext{
* Corresponding author: Evy.Vereecken@kuleuven.be
} 
water plain is varied. Next, in Section 3 the results are shown and analysed. Finally, the main results are drawn and further discussed in Section 4.

\section{Methodology}

\subsection{Test sample configuration}

The presence of a (perfect) hydraulic interface contact when using kaolin clay is investigated based on samples composed of two specimen of the same brick material. To avoid that during the preparation of the test samples the water of the kaolin clay would be absorbed by the bricks, moistened bricks were used. The kaolin clay was prepared by mixing kaolin powder with distilled water by a 1:1 mass ratio. By use of a putty knife, a layer of the kaolin clay was applied at the contact surface of both bricks and the bricks were put together by gently sliding both kaolin clay surfaces. Then, to create a good contact between both samples, clamping screws were used to put the samples together (Fig. 1). This way, also the excess of kaolin clay was removed from between both brick samples. Next, cable ties were put around the composite samples in order to keep the samples together during the measurements (see section 2.3). The composite samples had a total height of $16 \mathrm{~cm}$. The height of the top and the bottom sample for the different composite samples is given in Table 1, and varied in order to analyse the impact of the distance between the contact interface and the water surface in the experiment. As a reference, a homogeneous sample of $16 \mathrm{~cm}$ high was analysed. The top and bottom surface of the test samples measured 4 $\mathrm{cm}$ by $4 \mathrm{~cm}$.

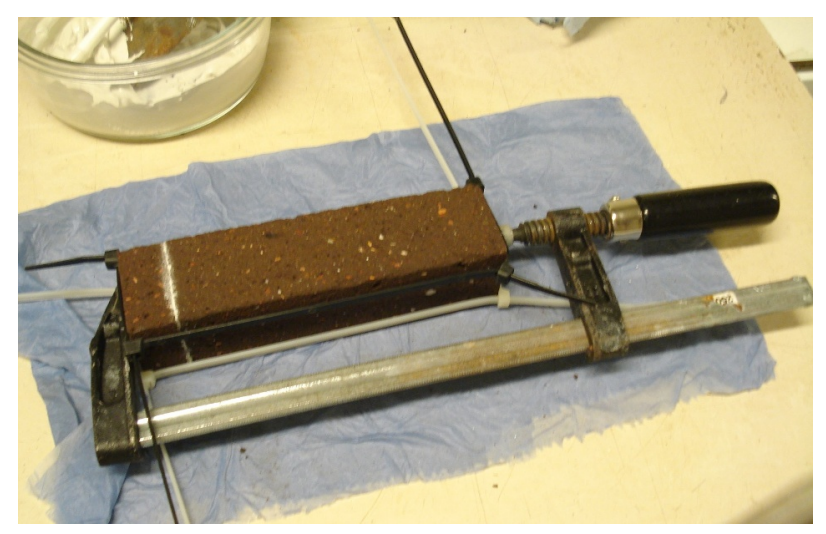

Fig. 1. Preparation of one of the composite test samples.

\subsection{Material properties}

To analyse the impact of the sample's absorptivity, both samples with a high and a low absorptivity were prepared, represented by 'brick 1' and 'brick 2', respectively (Fig. 2a). An overview of the basic hygric properties for both materials is given in Table 2. The moisture retention curve and the permeability curve are shown in Fig. 2b,c. Additionally, Fig. 2d shows for both samples the pore volume distribution. The higher absorptivity of Brick 1 agrees with the larger share of coarse pores for this brick.
Table 1. Height of the bottom and the top samples for the different test samples.

\begin{tabular}{|c|c|c|}
\hline Sample & $\begin{array}{c}\text { Height bottom } \\
\text { sample (cm) }\end{array}$ & $\begin{array}{c}\text { Height top } \\
\text { sample (cm) }\end{array}$ \\
\hline 1,2 & 2 & 14 \\
\hline 3,4 & 4 & 12 \\
\hline 5,6 & 6 & 10 \\
\hline 7,8 & 8 & 8 \\
\hline 9,10 & 10 & 6 \\
\hline 11,12 & 12 & 4 \\
\hline 13,14 & 14 & 2 \\
\hline $\mathrm{H} 1, \mathrm{H} 2$ & 16 & $/$ \\
\hline
\end{tabular}

Table 2. Basic material properties.

\begin{tabular}{|c|c|c|}
\hline Property & $\begin{array}{c}\text { Brick 1 } \\
\text { (high A Aap) }\end{array}$ & $\begin{array}{c}\text { Brick 2 } \\
\text { (low Acap) }\end{array}$ \\
\hline$\rho_{\mathrm{b}}\left(\mathrm{kg} / \mathrm{m}^{3}\right)$ & 1818 & 1549 \\
\hline Open porosity $(\%)$ & 32.6 & 41.3 \\
\hline $\mathrm{W}_{\text {cap }}\left(\mathrm{kg} / \mathrm{m}^{3}\right)$ & 210 & 256 \\
\hline$\mu_{\mathrm{dry}}(-)$ & 11.6 & 14.6 \\
\hline $\mathrm{A}_{\text {cap }}\left(\mathrm{kg} /\left(\mathrm{m}^{2} . \mathrm{s}^{0.5}\right)\right)$ & 0.61 & 0.26 \\
\hline
\end{tabular}

\subsection{Imbibition experiment}

The imbibition experiments were performed on oven dried samples (Fig. 3). To facilitate the measurements, the clamping screws were gently removed before starting the imbibition experiment, while the cable ties were left around the samples in order to keep a good contact between both samples. A single measurement on a composite sample kept together with clamping screws showed a similar behaviour as when using the cable ties only. Removing the clamping screws is thus allowed. To exclude possible differences in the results due to the use of the cable ties, these were also put around the homogeneous sample. Though, also here a control measurement on a homogeneous sample without cable ties showed a similar behaviour. The samples were put on bars and a water level of approximately $1 \mathrm{~mm}$ was provided. No foil was applied around the samples, so evaporation was not excluded. Though, this effect is expected to have no impact on the conclusions. 
a)
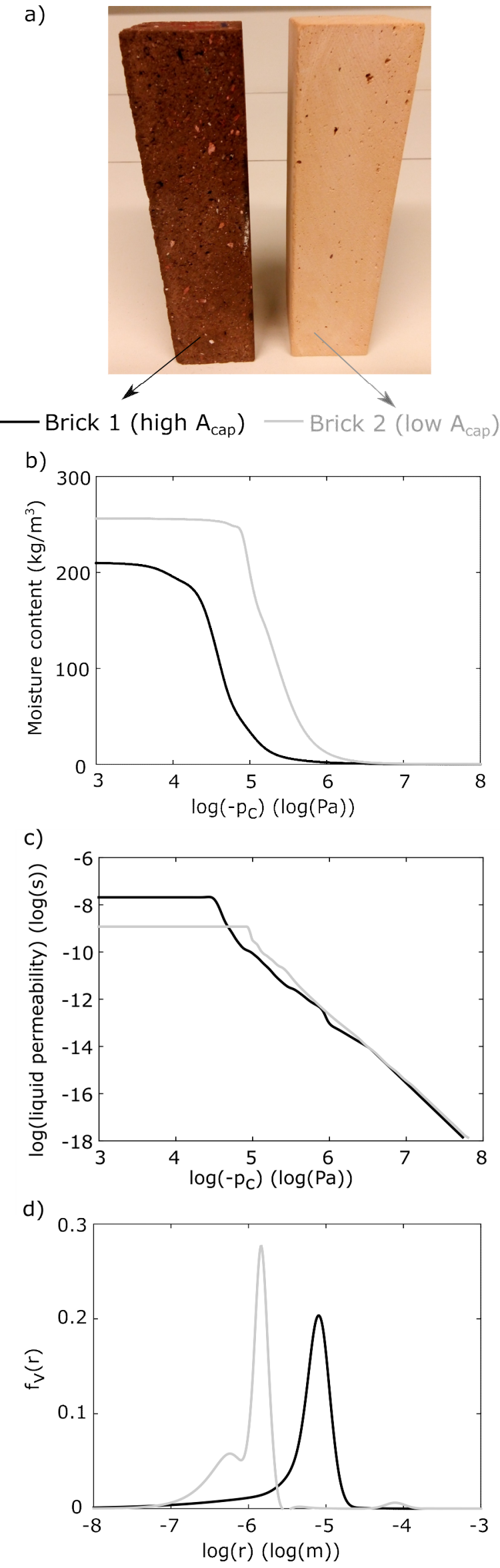

Fig. 2. (a) High and low absorptive brick, (b) moisture retention curve starting from $\mathrm{w}_{\text {cap }}$, (c) permeability curve and (d) pore volume distribution.

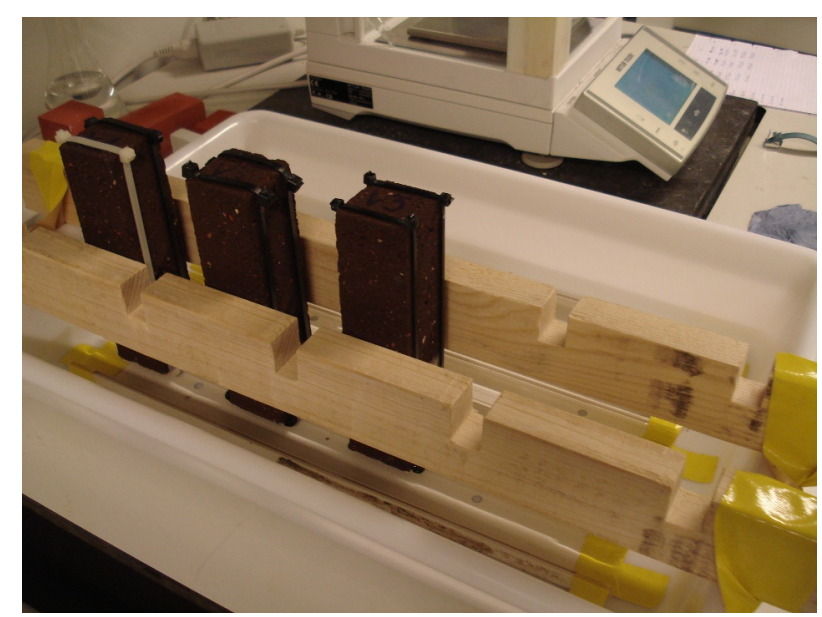

Fig. 3. Imbibition experiment on some of the test samples. The wooden bars are placed to avoid the samples falling in the water in case of instability.

\subsection{Hydraulic interface resistance estimation}

In a next step, the presence of a hydraulic interface resistance is analysed by comparing the experimental output of the imbibition experiments with the output of numerical simulations performed with Delphin 5 [12]. Thereto, at the position of the contact interface a $1 \mu \mathrm{m}$ thick control volume is implemented. The moisture permeability of this control volume is defined by an interface permeability $K_{I F}$ (s) calculated by:

$$
K_{\mathrm{IF}}=d / R_{\mathrm{IF}}
$$

with $d$ the thickness of the control volume $\left(1 \cdot 10^{-6} \mathrm{~m}\right)$ and $R_{I F}(\mathrm{~m} / \mathrm{s})$ the interface resistance searched for. The interface resistance is assumed to be a constant. This means that a potential capillary pressure or moisture content dependency is neglected. The other properties of the interface layer are set equal to the brick properties. The interface layer thus has no hygroscopic capacity.

\section{Results}

\subsection{Experimental output}

Fig. 4 shows the water uptake curve measured for the samples composed of (a) the high absorptive bricks and (b) the low absorptive bricks. For the high absorptive brick composites (Fig. 4a), different water uptake curves can be observed. As long as the water front does not reach the interface layer, the water uptake curve is shown to be equal to the curve achieved for the homogeneous brick sample. When reaching the contact interface, a slower water uptake is observed. Hence, the smaller the distance between the interface and the water plain, the more the curve deviates from the curve for the homogeneous sample. For Sample 13 and 14, with a distance of $14 \mathrm{~cm}$ between the contact interface and the water plain, the interface layer no longer has a visible impact on the water uptake curve.

For the samples composed of bricks with a low absorptivity (Fig. 4b), no distinct difference is found 

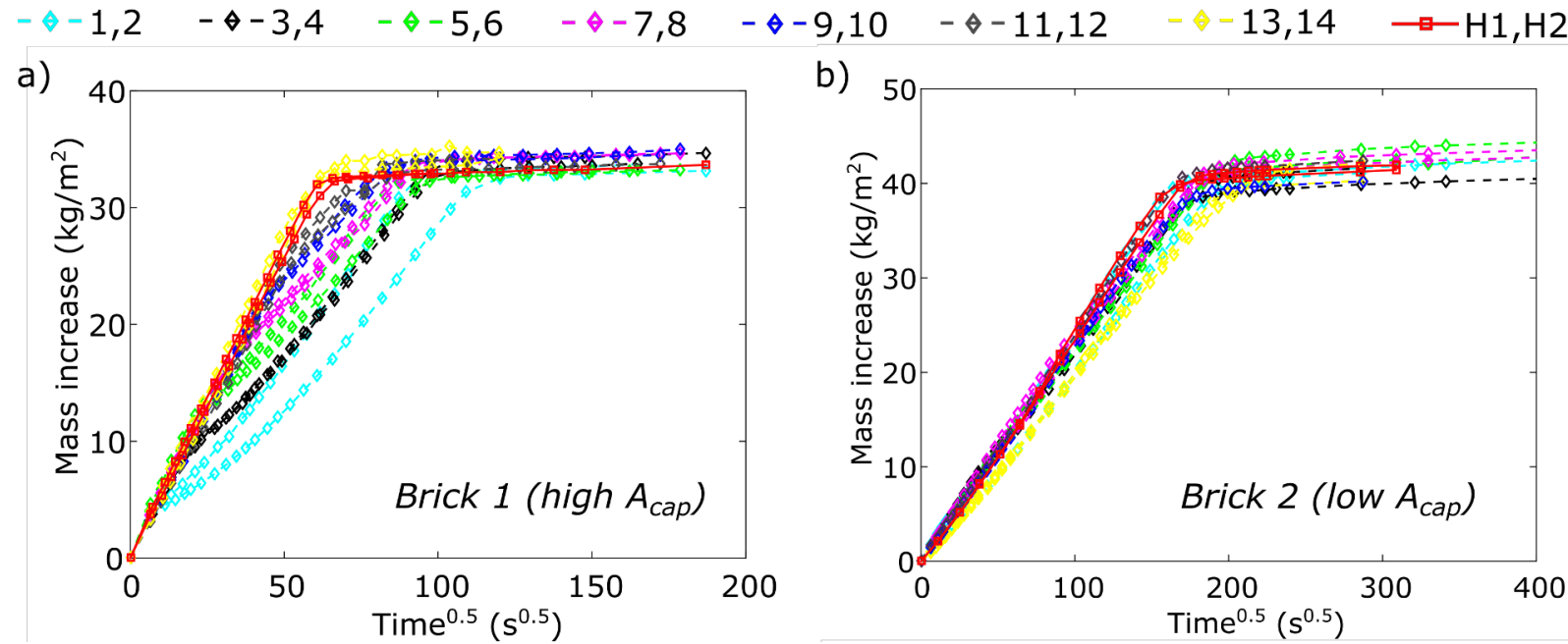

Fig. 4. Water uptake curve for (a) high absorptive brick and (b) low absorptive brick. H1 and H2 denote the homogeneous samples, the other samples are composite samples (the exact configuration for each of the samples is given in Table 1).

between the water uptake curves of the composite samples and the homogeneous samples. Small deviations between the different curves can be attributed to small differences between the brick samples, as confirmed by the random order of the different curves. Hence, no interface is present, or, if present, it has no impact on the water uptake curve.

\subsection{Numerical output}

\subsubsection{High absorptive bricks}

Fig. 5 compares, for the samples composed of the high absorptive bricks, the measured data with the numerical output. For each of the configurations, the experimental output measured for two test samples is shown. As a reference and validation of the brick properties, Fig. 5a first shows the results for the homogeneous sample. A good agreement is found. Fig. 5b till Fig. 5h show the experimental results for the different composite configurations, together with the numerical simulations for a set of R $\mathrm{IF}_{\mathrm{F}}$-values. For the samples with the smallest distance between the interface contact and the water plain (Fig. 5b) and thus with the largest deviation from the water uptake curve achieved for the homogeneous sample, the experimental output shows a small difference between both measured samples. An interface resistance $R_{I F}$ between 6000 and $12000 \mathrm{~m} / \mathrm{s}$ is found to yield a good agreement with the experimental data. As a comparison, the water uptake curves achieved when implementing no interface resistance $\left(R_{I F}=0 \mathrm{~m} / \mathrm{s}\right.$, as for the homogeneous samples) and an interface resistance of $100000 \mathrm{~m} / \mathrm{s}$ are shown and are found to respectively over- and underestimate the water uptake.

Next, the water uptake curve is simulated for the composite samples with a larger distance between the contact interface and the water plain (Fig. 5c-h). Also for these samples, an interface resistance $\mathrm{R}_{\mathrm{IF}}$ in the range of $6000 \mathrm{~m} / \mathrm{s}$ and $12000 \mathrm{~m} / \mathrm{s}$ is found to result in a good agreement between experimental and numerical output.
Moreover, the larger the distance between the contact interface and the water plain, the better the numerical output achieved without an interface resistance matches with the experimental output. The output becomes less sensitive to the presence of an interface resistance. For Sample 13 and 14, with a distance of $14 \mathrm{~cm}$ between the contact interface and the water plain, the curves achieved with RIF in the range between $6000 \mathrm{~m} / \mathrm{s}$ and $12000 \mathrm{~m} / \mathrm{s}$ still coincide with the curve obtained without an interface resistance, while also the impact of an interface resistance of $100000 \mathrm{~m} / \mathrm{s}$ becomes less pronounced.

\subsubsection{Low absorptive bricks}

For the samples composed of the low absorptive bricks, the water uptake curves behave similar as measured for the homogeneous sample (see Section 3.1). Therefore, for these samples, Fig. 6 shows only the measured curves of Sample 1 and Sample 2 for comparison with the numerical simulations. The numerical simulations are performed for the configuration with a distance of $2 \mathrm{~cm}$ between the contact interface and the water surface, as a sample with a contact interface close to the water surface is expected to be the most sensitive to the interface resistance. A numerical simulation without any interface resistance shows a good agreement with the experimental data of Sample 1 (Fig. 6a). Furthermore, by assuming R $\mathrm{RF}$ in the range of $6000 \mathrm{~m} / \mathrm{s}$ and $12000 \mathrm{~m} / \mathrm{s}$, as estimated for the samples composed of the high absorptive bricks, a good agreement is found as well. Only a small kink near a mass increase of $5 \mathrm{~kg} / \mathrm{m}^{2}$ and a slightly less steep slope from that point on can be observed (almost not visible). By increasing the interface resistance, this effect is gradually more pronounced (Fig. 6b). An $R_{I F}$ between $20000 \mathrm{~m} / \mathrm{s}$ and $50000 \mathrm{~m} / \mathrm{s}$ results in a reasonable agreement with the experimental curve of Sample 2. Though, small deviation in the properties of the brick, not included in the simulations, partially induce this behaviour. The sensitivity to the interface resistance diminishes for higher distances between the contact interface and the water plain (not shown). 


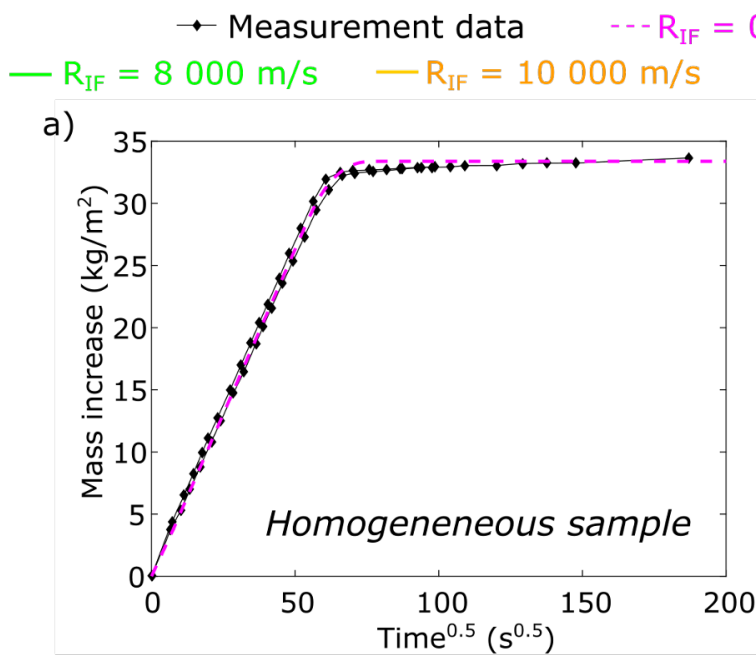

c)

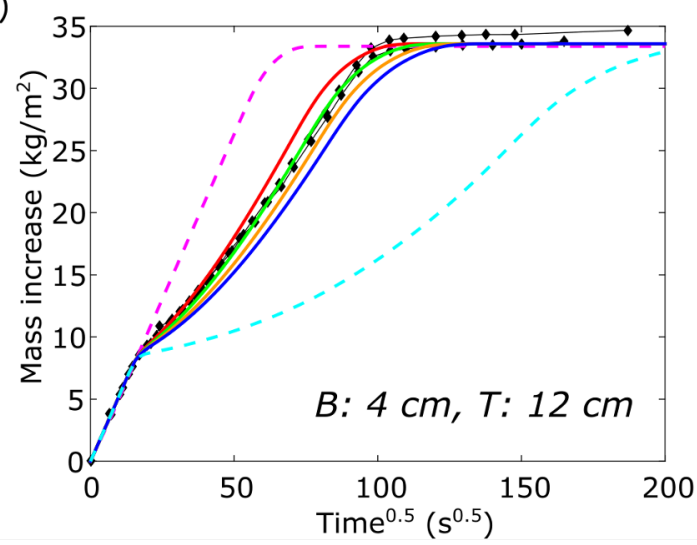

e)

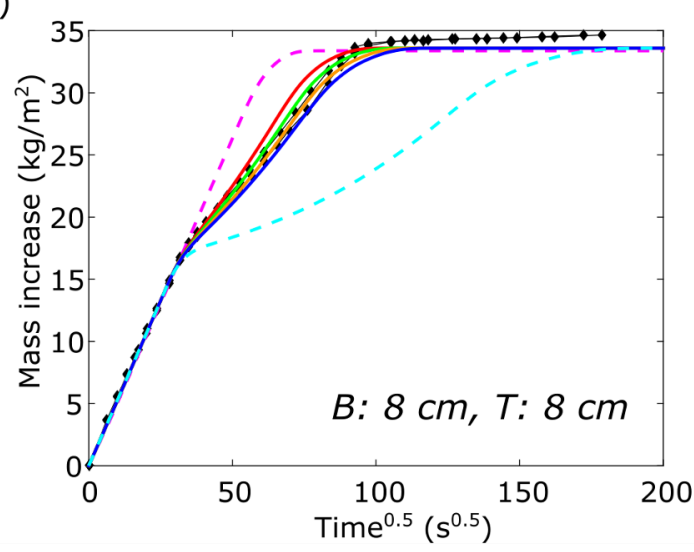

g)

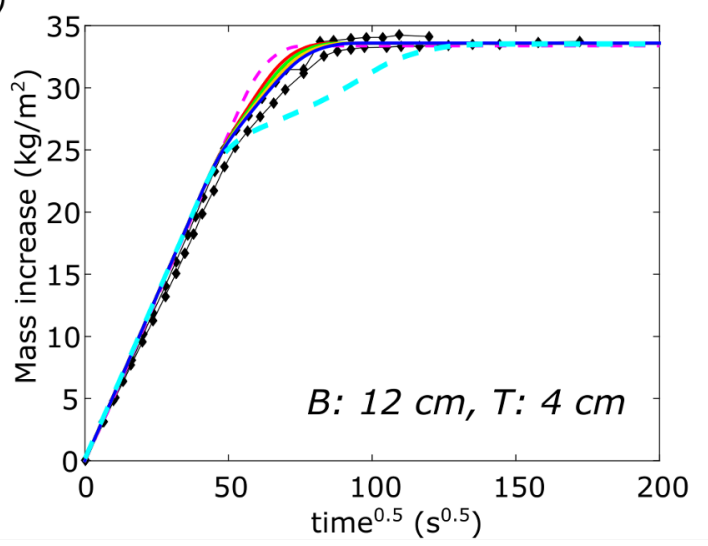

b)

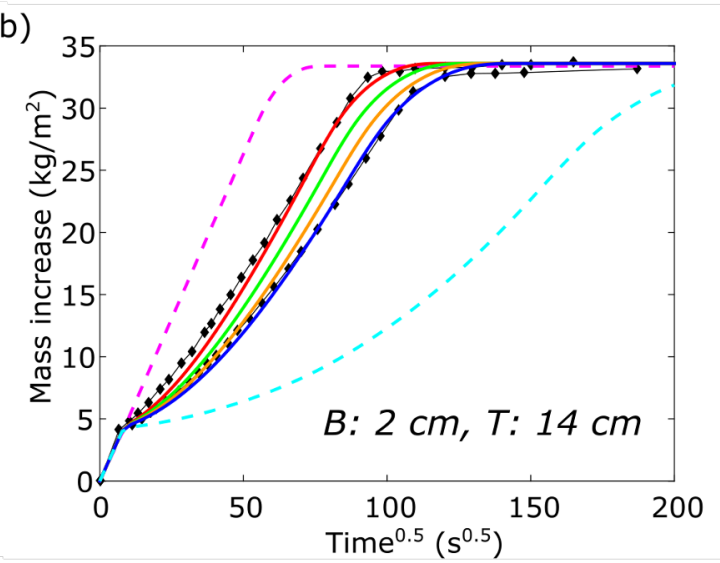

d)

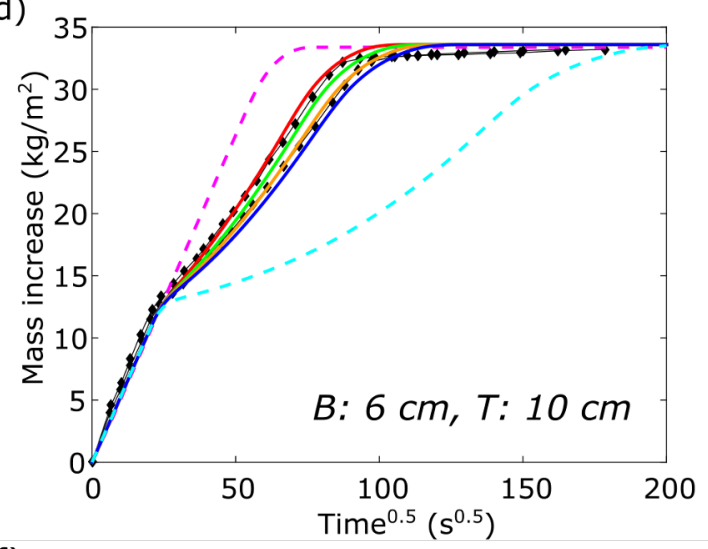

f)

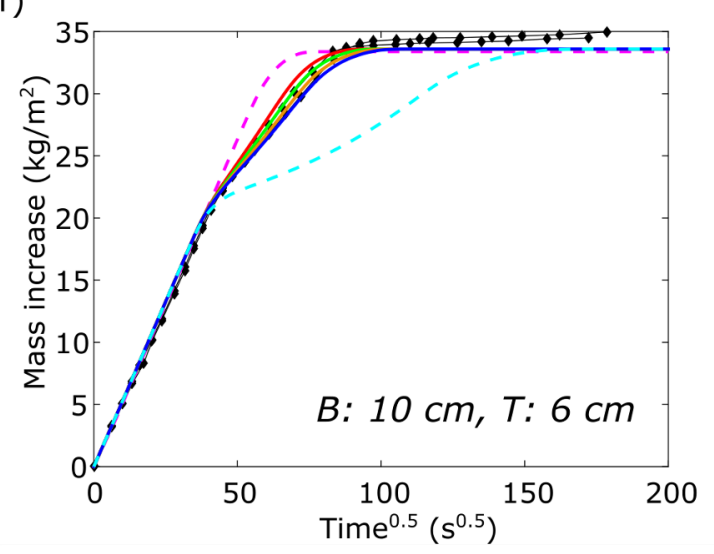

h)

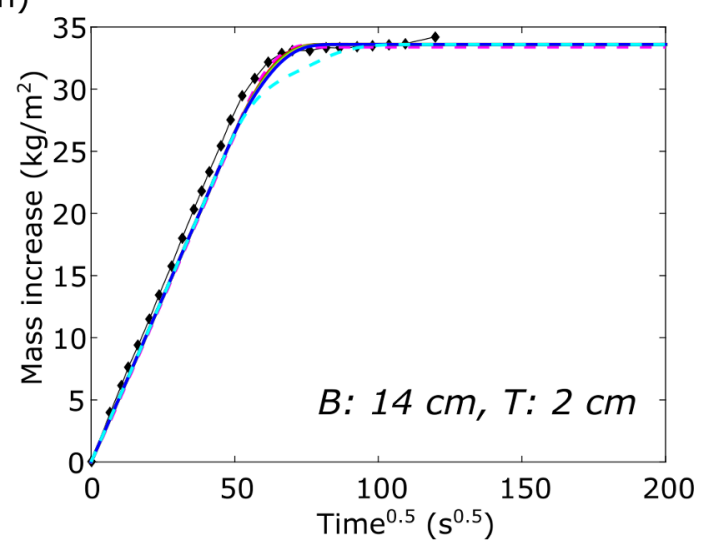

Fig. 5. Comparison between experimental and numerical output for the high absorptive brick: (a) homogeneous samples,

(b-h) composite samples with different combinations of height for the bottom (B) and top (T) sample. For the composite samples, different $\mathrm{R}_{\mathrm{IF}}$-values are applied in the numerical simulations. 

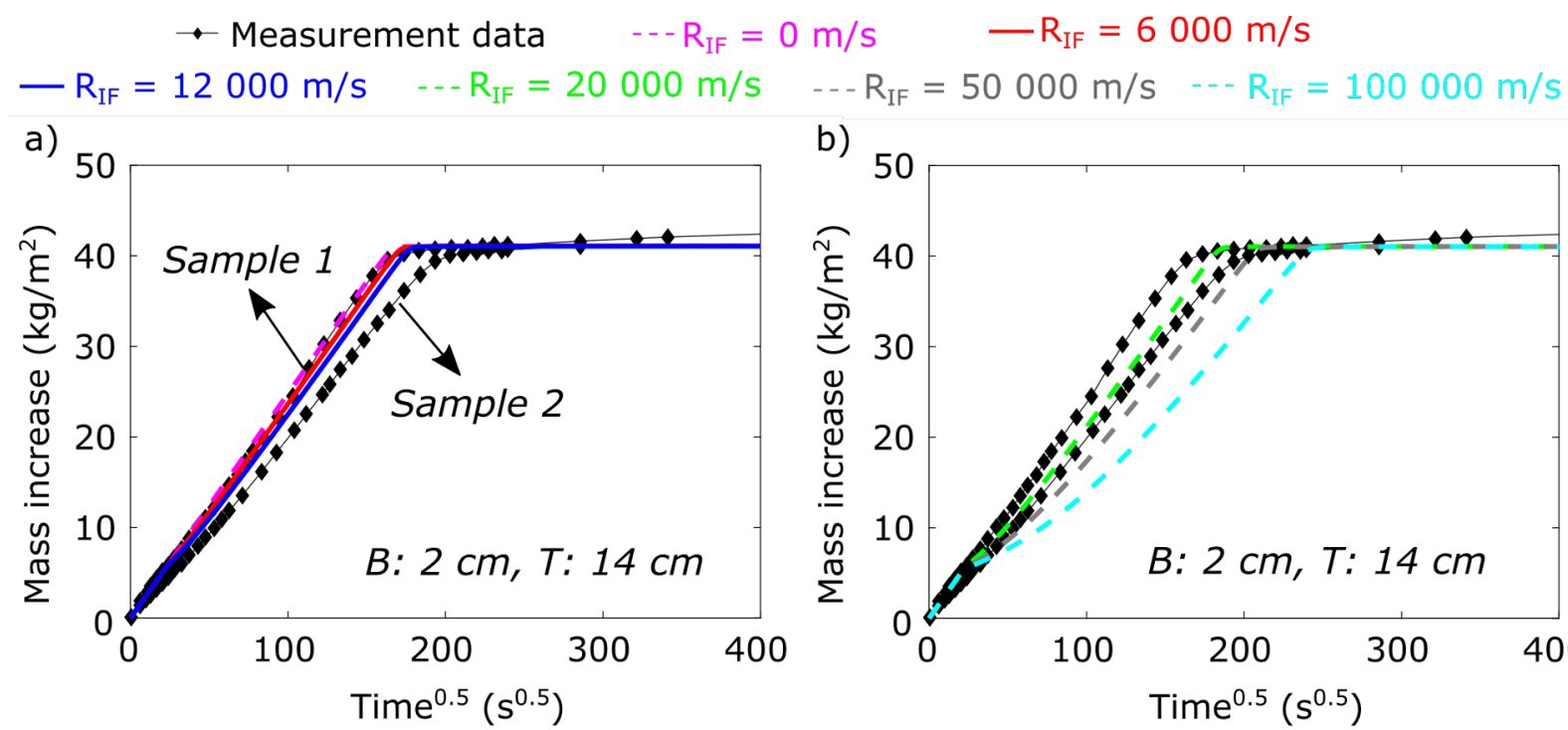

b)

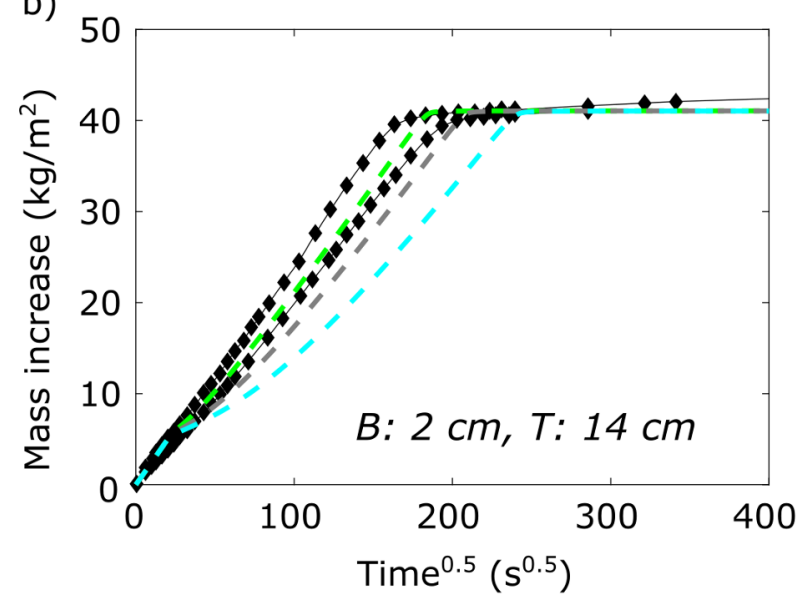

Fig. 6. Comparison between experimental and numerical output for the low absorptive brick: (a) no interface and RIF as estimated for the high absorptive brick samples, (b) impact of higher RIF-values.

\section{Discussion and conclusions}

Imbibition experiments on composite samples with a layer of kaolin clay revealed that the use of kaolin clay between materials does not provide a perfect hydraulic interface resistance in case of a high absorptive material. For samples composed of high absorptive bricks $\left(\mathrm{A}_{\text {cap }}=\right.$ $\left.0.61 \mathrm{~kg} /\left(\mathrm{m}^{2} \mathrm{~s}^{0.5}\right)\right)$ a hydraulic interface resistance between $6000 \mathrm{~m} / \mathrm{s}$ and $12000 \mathrm{~m} / \mathrm{s}$ was found to yield a good agreement with experimental data. The impact of the hydraulic interface is more pronounced for composite samples with an interface contact closer to the water plain. In case of a large distance between contact interface and water plain, a larger range of values for the interface resistance results in a good agreement between measured and simulated water uptake curve, making it harder to define a correct interface resistance. Based on this, it can be recommended to opt for test samples with a small distance between the contact interface and the water plain when estimating the interface resistance based on water uptake curves.

For bricks with a low absorptivity, the impact of a potential interface resistance was not clearly pronounce in the water uptake curves. Though, by implementing the interface resistance in the order of magnitude as determined for the high absorptive bricks, numerical simulations show also for these samples a good agreement with the experimental output. Hence, also for the low absorptive bricks a hydraulic interface might be present. The sensitivity to this interface resistance is however much lower in this case.

The knowledge on the order of magnitude of the interface resistance for typical material interfaces in practice is scarce. In a few studies an interface resistance has been estimated. For instance, Derluyn et al. [3] inferred an interface resistance of $1.25 \times 10^{10} \mathrm{~m} / \mathrm{s}$ between a brick and a wet cured mortar and of $2.5 \times 10^{10} \mathrm{~m} / \mathrm{s}$ between a brick and a dry cured mortar. Obvious these values are much larger than the interface resistance in the order of $9 \times 10^{3} \mathrm{~m} / \mathrm{s}$ for the 'perfect' hydraulic contact pursued in the current paper. The estimated value fall outside the accuracy of the interface resistance estimated for the real imperfect hydraulic contact between the (low absorptive) brick and mortar studied in [3]. Further research should give a better view on the type of composite samples and the imposed boundary condition for which the interface resistance caused by the kaolin clay can be an issue in the analysis of the real interface resistance. Additionally, the study should be extended with an analysis of the moisture profiles in the composite samples. Possibly, this way the $\mathrm{R}_{\mathrm{IF}}$ range for which a good agreement between experimental and numerical output is obtained can be reduced and the validity of a constant interface resistance can be further investigated.

Evy Vereecken is a postdoctoral fellow of the Research Foundation (FWO) - Flanders, Belgium (FWO project $12 J 5219 N)$. This financial support is gratefully acknowledged.

\section{References}

1. H. Brocken. Moisture transfer in brick masonry: the grey area between bricks. PhD Thesis, TU Eindhoven, The Netherlands. (1998).

2. H. Brocken, M. Spiekman, L. Pel, K. Kopinga, J. Larbi. A water extraction out of mortar during brick laying: a NMR study, Mater Struct, 31:49-57 (1998).

3. H. Derluyn, H. Janssen, J. Carmeliet, Constr Build Mater, 25:3685-3693 (2011)

4. K. Calle, T. De Kock, V. Cnudde, N. Van den Bossche, J Build Phys, 43(3) : 208-228 (2019).

5. A. Guimarães, J. Delgado, A. Azevedo, V. de Freitas. Constr Build Mater, 162 :480-488 (2018).

6. A. Holm, M. Krus, H. Künzel. Feuchtetransport über Materialgrenzen im Mauerwerk. International Zeitschrift für Bauinstandsetzen, 2. Jahrgang, Heft 5. (1996) 
7. C. Groot. Effects of water on mortar-brick bond. Heron, 40:57-70 (1995).

8. E. Vereecken, S. Roels, XIII Int. Conf. on DBMC, 527-534 (2014)

9. E. Vereecken. Hygrothermal analysis of interior insulation for renovation projects. PhD Thesis, $K U$ Leuven, Belgium. (2013)

10. W. Depraetere, J. Carmeliet, H. Hens. Moisture transfer at interfaces of porous materials: Measurements and simulations. RILEM International Workshop 'Historic Mortars: Characteristics and test'. University of Paisley, Scotland, 12th-14th May 1999.

11. V. Voronina. Salt extraction by poulticing : an NMR study. PhD Thesis, TU Eindhoven, The Netherlands. (2011).

12. Delphin, Simulation program for the calculation of coupled heat, moisture, air, pollutant and salt transport. http://bauklimatikdresden.de/delphin/index.php?aLa=en 